\title{
Role of Talk Shows Raising Political Awareness among Youth (Study Conducted in District Toba Tek Singh)
}

\author{
Nabila Naz * \\ Dr. Yasir Nawaz * \\ Muhammad Ali \\ Department of Sociology, University of Agriculture, DG khan campus \\ Dr. Nisar Hussain \\ Department of Agri.Ext. College of Agriculture, DG khan, \\ Shahzad Khaver Mushtaq * \\ Rab Nawaz * \\ * Department of Sociology, University of Sargodha
}

Doi:10.5901/ajis.2014.v3n1p223

\begin{abstract}
Youth is almost 60 percent in Pakistan, who can play a vital role in the progress of the country especially political participation of youth is very effective for the development. The aim of this study was to investigate the effective role of talk shows in raising political awareness. It has been always pivotal to research, especially in social sciences to study the characters that shape our perception about politics. It was known from the study literature that Talk shows are influence the youth perception and also aware the political awareness. Study was quantitative nature population was selected from the district of Toba Tek Singh. Total sample of 150 respondents were taken through simple random sampling. Data collected from Male and female youth. Questionnaire was use as a tool to collected data. SPSS (statically package for social sciences) was used for data analysis. Statistical analysis Chi-Square secure test was taken to check the relationship between the independent and dependent variables. The finding shows that media is raising awareness about politic among youth, but also there are some misinterpretations prevails there.
\end{abstract}

\section{Introduction}

When someone brings news to you- you should investigate its credibility first (Quran). It is the media for the masses that helps them to get information about a lot of things. Media help to form opinions and make judgments regarding various issues. It is the media which keeps the people updated and informed about what is happening around them in the world. Everyone can draw something from it.Television has the potential to generate both positive and negative effects, and many studies have looked at the impact of television on society, particularly young ones and adolescents. Not all television programs are bad, but data showing the negative effects of exposure to violence, inappropriate sexuality and offensive language are convincing.According to previous researches show that negative effects of media on children are manifested in terms of their changing mental set-up and the declining quality of their lifestyle. Children, who should invest their time in reading good books, studying, playing outdoor, exercising and engaging in social activities, today, spend their evenings glued to the television. Parents play an important role in their children's social learning, but if a parent's views are not discussed explicitly with children, the medium may teach and influence by default. Other media, such as magazines, radio, video games and the Internet, also have the potential to influence youth's eating habits, exercise habits, buying habits and mental health. If children are allowed to be exposed to these media without adult supervision, they may have the same deleterious effects as television (Voyez,2003).

Print is the oldest media of mass communication. Newspapers can reach greater masses of public. Radio Pakistan 
is the $1^{\text {st }}$ step of media.14 august 1947 when $1^{\text {st }}$ time these words were spoken instead of "this is all India radio by ZahoorAazher in English and Mustafa Ali Hamadani in Urdu" building of radio Pakistan Karachi built in 1950. In Pakistan television was $1^{\text {st }}$ introduce in the excitation near MezareQuiad on 16 September 1955 it was a small source of entertainment and short circuit television for audience to watch the miracle invention,26 November 1964 Pakistan television came into being (Pakistan corporation limited PTV). $1^{\text {st }}$ official television station commenced transmission telecast from Lahore. In Karachi 1966; In Peshawar and Quetta in 1974 original telecast work in black and white PTV launched a full-scale satellite telecasting services in 1991-1992 whereas digital TV telecast services was launched in 1999. $1^{\text {st }}$ ever live transmission from Australia via satellite on 22th December $1972.1^{\text {st }}$ ever colure transmission in Pakistan 20th December 1976.Today PTV spilt up into original channel feed. just like PTV home, PTV news, PTV national, PTV Bolan (Bolouchi), PTV Global (dish network), 15 July $19901^{\text {st }}$ private channel NTM (network television marketing) was launched.1 $1^{\text {st }}$ march 2002 gen PrervazMushraf issued the ordinance for launching the private channels. Nearly 100 channels can see on TV like GEO, HUM, ARY, DUNIA, SAMA, WAQAT etc which is based on news entertainment sports religion informative documentary music cooking business political etc. AabdulRazaqYaqoob (A.R.Y) has leading private channels in chain in Pakistan (Javaid, 2012).

The history of TV talk shows is long, as it represents one of the first formats of programming in television history. While the greater part of the early shows was geared towards politics and government, a number of celebrity-oriented shows began to start up during the 1960s. During the 1970s, many of the game shows that played during the daytime began to get replace by talk shows (chavis, 1993).

Talk shows is almost always anchored or framed by an announcer or host figure. May talk shows be defined, in Erving Goffman's terms, as "fresh talk," that, talk that appears to be generated word by word and in a spontaneous manner. Though it is always to a degree spontaneous, talk shows talk is also highly structured. It takes place in ritualized encounters and what the viewer sees and hears on the air has been shaped by writers, producers, stage managers and technical crews and tailored to the talk formulas of talk shows (VickramBahl, 2010). A talk show is a television program or radio program where one person discusses various topics put forth by a talk show host (S. Brain, 2010).

Sometime, talk show features a panel of gusts, usually consisting of a group of people who are learned or who have great experience in relative to whatever issue is being discussed on the show for that episode. Sometime a single guest discusses their work or area of the expertise with the host or co-host. A call-in show takes live phone calls from callers listening at home, in their cars and gathering of friends etc. TV talk shows often featured celebrity guests who talk about their work, personal lives as well as their latest scandals, TV shows, projects and public meetings (Burch, 2011).

There are many Pakistani talk shows that are fulfilling our masses needs. For example GEO TALK SHOW "AJ RAT KAMRAN K SATH","CAPITAL TALK "in this talk shows ask soft questions about specially about our country crises due to this people like their programs, because in his talk show every one fights and he is expert in engaging people in fight with each other.. HUM SAB UMEED SE HEIN" funny program in which media criticizes the politicians such a great political programs, if we talk about Express talk show program "KalTak" has a very informative intro mostly and there is also a book in which the intros of "KalTak" are mentioned that was one of the popular books in Pakistan. Similarly "Hasbe-Haal" is one of the most popular Pakistani Talk Show of DUNIA. In this talk show there are lots of things for viewers to learn, this is in true sense a real learning talk show. In a very light way the Azizi criticize the wrong doings of government as well as other political parties of Pakistan. There are some other Pakistani Talk Shows that are doing great job(Jamil, 2010).

But there is another aspect of these talk shows. You can't believe it that now people don't watch talk shows as an informative program but just for the enjoyment. You will find representatives of different parties fighting like dogs in the Pakistani Talk Shows. There are some examples in which the participants also use adult and abusive language for their opponents in the live Pakistani talk shows and the TV channels highlighted these comments again and again in bulletins. In every Pakistani talk show there must be fight between participants, often the abusive language changed into serious fight and they started fighting as dogs. (Qureshi, 2009)

Politics means social relations involving authority or power" and to the methods and tactics used to formulate and apply policy. According to Hegel, Political History "is an idea of the state with a moral and spiritual force beyond the material interests of its subjects: it followed that the state was the main agent of historical change" (Hegel, 1991).Aristotle concludes that "man is a political animal": we can only achieve the good life by living as citizens in a state.

Imagination about a state is at the start and there is not any state could not live without state. Aristotle gave the point of view about state and he also include politics in that idea of state because politics is found at start level but with the passage of time changes accurse in it and it grows up and in its present shape. Talk shows gave a new medium to politics and due to its people are much aware of it as compare to past and also tale interest in politics more than past. 
Today people not only think over it but also talk about politics they know each and every thing today due to political talk shows and also can judge who is better and should be next leader and can work better for their country(Politics Portal, 2012).

Talk shows play very important and fundamental role in raising political awareness. Their role cannot be ignored for development in political sector .Identification of the role of talk shows in raising political awareness and problems is very important .This study designed to analyze the role and effects on society. The research finding of present study helpful in analyzing the major socio-economic problems of talk shows. It will be helpful in new strategies for the betterment of future of talk shows for raising the political awareness. Talk shows raise political awareness among youth that they watch what is going on and can take step to keep in front of them the circumstances that what should they have to do and how to behave according to these circumstances against political issues. Due to these talk shows masses know about their political leader and also know about their activities and they also can judge who is right and who is wrong and who should b appointed for leadership for next time. Talk shows are also a source of accountability which shows and inform the viewers about their scandals. We can easily today know about their life style their habits and also about their good and wrong deeds its all due to media and talk shows which represents them so closely that their fans can know about each and every thing related to them.

Talk shows are source of our judgment and perceptions about political leader they also become a cause of divergence at the start youth have no idea about their rights and they only what their families order them and they just waist their right of vote and do not use in well manner. Their voting behavior is same as their forefathers have been done and no change accord but when political talk shows get fame in our society and people are influence from them than it bring change specially in their thinking, voting behavior and specially today our youth is much aware of politics and political leaders and also know about right and wrong. News channels are some time become ethnic and spread wrong news which are totally for away from realty and they promote wrong news and also collect wrong data against political leaders and due to talk shows they invited the victim and ask the question according to that news and confirm how much reality is found in it and what is their own point of view about that news and either that news right or not so talk shows is also can called a way where reality is found and get. A negative impact of political talk shows is some time it become so aggressive and start to ask personal questions due to which political leaders start to cal abuses to each other and bad impact is promoted to viewers and it is just due to anchor who ask such questions which make the show so aggressive and gust have to force to act roughly. Talk shows are also can called the source of showing duel personality as such in a way that when our political leaders visit abroad countries and meet with their political leader and talk to them in a convenient manner and ask them for help and request them that they are poor and also have masses who live from hand to mouth but when they came back to their country and they started to self praise that they are very genius and can solve and handle everything which shows their duel personality and people make judgment about them.

\section{Objectives}

- To investigate the political awareness among youth.

- To find out the knowledge of respondents about politics.

- To analyze the role of talk shows in raising awareness about politics.

- To explore the beneficial and harmful effects of media on youth's mental and physical health.

\section{Research Methodology}

There are three types of studies: descriptive, causal, and exploratory. This intended research is basically descriptive for the present research preferable (Stbbins, 2001). This research is basically descriptive, descriptive research involves collecting data in order to test hypotheses or answer questions concerning the status of the subject of the study (Gay, 1996). The method of this research qualitative, Qualitative research is"formal, objective, systematic process in which numerical data utilizes to obtain the information about the world" (Burns and Cormack, 1991).

The selected universe for this study was conducted on youth of district Toba Take Singh. The 75 respondents of this research were taken as female youth and 75 respondents of this research were taken as male youth from the Distt.Different collages selected through simple random sampling technique from three tahsil of Toba Tek Singh district. The total sample size was consisting of 150 respondents including both boys and girls. Questionnaire was developing under the supervision of the advisor to find out the attitude of women towards reproductive health. Questionnaire will develop on the basis of hypothetical frame work.Data collected through questionnaires which consist on close ended 
questions from urban areas.

Pre- testing of the questionnaire is the condition of data collection. The ambiguities encountered during this trial and error stage were carefully rectified on revision and modification of the interviewing schedule (Goode and Hatt, 1952).Before starting actual data collection activity pre-testing on 20 respondents was carries out to examine the workability and sensitivity of the questionnaire.Quantitative data was analyzed through various statistical techniques as univariate /descriptive, bivariate and multivariate techniques. In univariate analysis such as frequency, percentage and measures of central tendency (mean, standard deviation) were used to describe the data. In bivariate analysis, relationships among different variables were examined through applying chi-square and gamma tests.

In this section different techniques used to analyze the data are described. The study employed descriptive statistics to summarize and describe the data whereas inferential statistics such as Gamma statistics were used to examine the relationship between predicators and response variables.

\section{Results and Discussions}

\subsection{Finding of Descriptive analysis}

Data shows that majority 44.7 percent of the respondents lies in the age limit is of $21-23,29.3$ percent of respondent's lies in the age category of 18-23, 26.0 percent respondent's lies in the range of 24-26. So the above table results that respondent youth is well mature to take their own decisions. Approximately half of respondents (46.7\%) were males and other half (53.3\%) of them were females. Data describes that respondent marital of $12.0 \%$ respondents were married, $85.3 \%$ were single $2.7 \%$ were divorce. It shows that majority respondents' were single.Family structure of $31.3 \%$ respondents was living in nuclear, a large majority $56.7 \%$ were joint family system, $12.0 \%$ were in extend family system. Data demonstrates that father's occupation of $15.7 \%$ respondents was business, a large majority $52.7 \%$ were government job, $13.3 \%$ were from agriculture field and $18.7 \%$ were related to private job. Findings reveals that 26.7 percent of the respondents were under graduate, 50.7 percent of them were Graduate and 22.7 percent of them were post graduate.28.0\% respondents had income less than 20 thousands, $46.0 \%$ had income more than 30 thousands, $11.3 \%$ fell in category of more than 40 thousands, $14.7 \%$ had income more than 50 thousands income. Majority 96.7 percent of respondents have access to media and 3.3 percent respondents have no any type of media access. Mean value of the response which is 1.4000 with standard deviation .49154.Majority 79.3 percent of respondents had know about the use of computer and 20.7 percent respondents did not know about any kind of use of computer. Mean value of the response which is 1.2067 with standard deviation .40627 .only 58.0 percent of respondents had cast their vote according to their own will and 42.0 percent respondents did not cast their vote according their own will. Mean value of the response which is 1.4200 with standard deviation .49521.

Data indicates that respondents watch news channel $38.0 \%$, entertainment channel $36.7 \%$, sports channel $16.7 \%$ and documentary channel $8.7 \%$. Mean value of the response which is 1.9733 with standard deviation .94085 . Table 13 indicates that respondents like political talk shows especially which were base on critical analysis $38.0 \%$, conversation $26.0 \%$, dialogue $18.0 \%$ and problem statement18.0\%. Mean value of the response which is 2.2800 with standard deviation1.04348. Data 14 indicates that $34.0 \%$ of respondents were regular listener, $34.0 \%$ rarely, $28.7 \%$ were regular and $3.3 \%$ are none of them. Mean value of the response which is 2.0133 with standard deviation .87460 .

Research findings indicates that $39.3 \%$ of respondents pay some attention to news about politics, $31.3 \%$ pay a little attention, $21.3 \%$ pay a little and $8.0 \%$ pay none. Mean value of the response which is 2.2600 with standard deviation .88560 . More than half i.e., $54.0 \%$ of respondents watch often program about election on TV, $28.0 \%$ regular, $14.0 \%$ watch sometime and $3.3 \%$ were never watch. Mean value of the response which is 1.9267 with standard deviation .74272. Only $43.3 \%$ of respondents attend often public meeting about election, $38.7 \%$ sometime, $16.7 \%$ respondents attend regular and $1.3 \%$ never attend. Mean value of the response which is 2.2467 with standard deviation .74127 . About $36.0 \%$ of respondents interested in politics somewhat, $31.3 \%$ very interested, $24.0 \%$ a little and $8.7 \%$ not at all. Mean value of the response which is 2.1000 with standard deviation .94656 . Nearly $35.3 \%$ of respondents were fairly satisfied with the democracy work in Pakistan, $24.0 \%$ not fairly satisfied, $23.0 \%$ not at all satisfied and $17.3 \%$ very satisfied. Mean value of the response which is 2.5333 with standard deviation1.03409.43.3 \% Respondents think that 100,000 People don't have access to safe drinking water, $15.3 \%$ said less than 100,000 , and $24.7 \%$ said 10 million and $16.7 \%$ said 1.1 billion. Mean value of the response which is 2.4267 with standard deviation1.94369. More than half i.e., $53.3 \%$ of respondents think that $1-24 \%$ of world population will live in stressed area, $35.3 \%$ goes with $25-49 \%, 6.0 \%$ goes with $50-74 \%$ and $5.3 \%$ goes with $75-99 \%$. Mean value of the response which is 1.6333 with standard deviation. 82264 . Data indicates that $43.3 \%$ of 
respondents had opinion that after getting involve against terrorism with America the change in economy of Pakistan was no effect, $32.7 \%$ constantly fall, $18.7 \%$ getting raise, $5.3 \%$ do not know. Mean value of the response which is 2.2467 with standard deviation1.81871. Findings indicates that $38.7 \%$ of respondents agree that news channels promote political awareness in youth whereas $37.3 \%$ strongly agree, 20.7 neutral .7\% disagree and 2.7 strongly disagree. Mean value of the response which is 2.2467 with standard deviation1.8187. 35.3\% respondents neutral that talk shows are preplan act, 34.7 strongly agree, 20.0 agree, $6.7 \%$ disagree and $3.3 \%$ strongly disagree. Mean value of the response which is 2.3867 with standard deviation 0.98843 .

Data indicates that $32.7 \%$ of respondents neutral talk shows presenter of different political parties whereas 30.7 agree, $30.0 \%$ strongly agree, 3.3\% disagree and 3.3\% strongly disagree. Mean value of the response which is 2.1867 with standard deviation1.01919. 38.7\% of respondents agree that media increase the awareness level of youth, 35.3\% strongly agree, $22.7 \%$ neutral whereas $2.0 \%$ disagree and $1.3 \%$ strongly disagree. Mean value of the response which is 1.9200 with standard deviation $1.90130 .31 .3 \%$ of respondents agree that talk shows influence the youth $32.0 \%$ strongly agree, $20.7 \%$ neutral, $12.7 \%$ disagree and $3.3 \%$ strongly disagree. . Mean value of the response which is 2.2467 with standard deviation1.12886.33.3\% of respondents agrees that media as source of learning, $28.7 \%$ neutral, and $28.0 \%$ strongly agree whereas $5.3 \%$ disagree and $4.7 \%$ strongly disagree. Mean value of the response which is 2.2000 with standard deviation1.10520.45.3\% of respondents neutral that talk shows trustworthy whereas $33.3 \%$ strongly agree, $11.3 \%$ agree, $9.3 \%$ disagree and .7\% strongly disagrees. Mean value of the response which is 2.5467 with standard deviation1.84016. About $34.0 \%$ of respondents agree that talk shows on news channels providing food full thought, $26.7 \%$ strongly agree, $26.0 \%$ neutral, $20.7 \%$ disagree and $2.7 \%$ strongly disagree. Mean value of the response which is 2.2133 with standard deviation1.10876.32.0\% of respondents neutral that news channels brought change in society, $28.7 \%$ agree, $24.0 \%$ strongly agree whereas $8.7 \%$ disagree and $6.7 \%$ strongly disagree. Mean value of the response which is 2.4067 with standard deviation1.18206.35.3\% of respondents agree that TV channels had objective to present political talk shows, $28.7 \%$ strongly agree, 26.0 neutral whereas $6.0 \%$ strongly disagree and $4.0 \%$ disagree. Mean value of the response which is 2.1667 with standard deviation1.113762.42.7\% of respondents agree that people getting knowledge about different issues through political talk shows, 23.3\% neutral, 20.0 strongly agree whereas $8.0 \%$ disagree and $6.0 \%$ strongly disagree. Mean value of the response which is 2.1467 with standard deviation $1.22823 .29 .3 \%$ of respondents neutral that people watched political programs just for sake of enjoyment not for getting information now a day's, $25.3 \%$ strongly agree, $24.3 \%$ agree whereas $14.0 \%$ disagree and $6.7 \%$ strongly disagree. Mean value of the response which is 2.5267 with standard deviation $1.19763 .39 .3 \%$ of respondents strongly agree that political parties fighting like dogs in political talk shows, $26.7 \%$ neutral, 22.7 agree whereas $6.7 \%$ disagree and $4.7 \%$ strongly disagree. Mean value of the response which is 2.3133 with standard deviation $1.04359 .34 .0 \%$ of respondents neutral that news on political parties were not spreading real information, $30.7 \%$ strongly agree, $24.7 \%$ agree whereas $7.3 \%$ disagree and $3.3 \%$ strongly disagree. Mean value of the response which is 2.3400 with standard deviation $1.03515 .37 .3 \%$ of respondents neutral that political talk shows providing information that can promote democracy, $26.7 \%$ strongly agree, $22.7 \%$ agree whereas $8.7 \%$ disagree and $4.7 \%$ strongly disagree. Mean value of the response which is 2.4600 with standard deviation $1.07834 .37 .3 \%$ of respondents neutral that political parties were play pivotal role in representative democracy, $30.7 \%$ strongly agree, $19.3 \%$ agree whereas $8.7 \%$ disagree and $4.0 \%$ strongly disagrees. Mean value of the response which is 2.4733 with standard deviation $1.02778 .30 .7 \%$ of respondents agree that political talk shows played vital role in developing political socialization in Pakistan, 30.7\% strongly agree, $30.0 \%$ neutral whereas 5.3\% disagree and $3.3 \%$ strongly disagree. Mean value of the response which is 2.2000 with standard deviation1.04271.

$36.0 \%$ of respondents neutral that political talk shows had no impact in villages, $26.7 \%$ strongly agree, $16.7 \%$ disagree whereas $16 . \%$ agree and $4.7 \%$ strongly disagree. Mean value of the response which is 2.6733 with standard deviation $1.07751 .38 .3 \%$ of respondents strongly agree that parties and politicians were more concerned with fighting each other with fighting other than with furthering the common interest, $29.3 \%$ agree, $23.3 \%$ neutral whereas $6.0 \%$ disagree and $2.7 \%$ strongly disagree. Mean value of the response which is 2.1400 with standard deviation $0.99684 .42 .7 \%$ of respondents strongly agree that many people think that their vote did not matter in elections, $25.3 \%$ neutral, $18.7 \%$ agree whereas $8.7 \%$ disagree and $4.7 \%$ strongly disagree. Mean value of the response which is 2.3800 with standard deviation $1.03412 .33 .3 \%$ of respondents strongly agree that some time politics were so complicated that someone like me could not understand what's going on, $0.3 \%$ neutral, $21.3 \%$ agree whereas $8.7 \%$ disagree and $6.0 \%$ strongly disagree. Mean value of the response which is 2.4467 with standard deviation1.10239. 


\section{Testing of Hypothesis}

5.1 Hypothesis 1: Greater the inclination toward listening/watching talk shows, the higher the chances of awareness raising among youth.

Association between age of the respondents and their perception about socio-economic determinants of rural migrants in urban setting

\begin{tabular}{|c|c|c|c|c|}
\hline \multirow{2}{*}{$\begin{array}{l}\text { Listening/ } \\
\text { watching talk } \\
\text { shows }\end{array}$} & & \multicolumn{2}{|c|}{ Political awareness } & \multirow[t]{2}{*}{ Total } \\
\hline & Low & & & \\
\hline Medium & High & & & \\
\hline Low & 7 & 19 & 8 & 34 \\
\hline \multicolumn{5}{|l|}{$20.6 \%$} \\
\hline $55.9 \%$ & $23.5 \%$ & $100.0 \%$ & & \\
\hline Medium & 15 & 53 & 13 & 81 \\
\hline \multicolumn{5}{|l|}{$18.5 \%$} \\
\hline $65.4 \%$ & $16.1 \%$ & $100.0 \%$ & & \\
\hline High & 6 & 5 & 24 & 35 \\
\hline \multicolumn{5}{|l|}{$17.1 \%$} \\
\hline $14.3 \%$ & $68.6 \%$ & $100.0 \%$ & & \\
\hline Total & 28 & 77 & 45 & 150 \\
\hline \multicolumn{5}{|l|}{$18.7 \%$} \\
\hline $51.3 \%$ & $30.0 \%$ & $100.0 \%$ & & \\
\hline
\end{tabular}

Chi-square $=14.23$, d.f. $=4$, Significance $=.042^{\star *}$, Gamma $=.208,{ }^{*}=$ Significant

Table 57 presents the association between listening watching talk shows and respondents political awareness. Chisquare value shows a significant association between listening/watching talk shows and political awareness. Gamma shows a positive relationship between the variables. It means if the respondents watching more political talk shows then they had also more political awareness. So the hypothesis "Greater the inclination toward listening/watching talk shows, the higher the chances of awareness raising among youth" is accepted.

\subsection{Hypothesis 2: Higher the education higher the political awareness.}

Association between education of the respondents and their perception about socio-economic determinants of rural migrants in urban setting

\begin{tabular}{|c|c|c|c|c|}
\hline Education & & Political awa & & Total \\
\hline & Low & & & \\
\hline Medium & High & & & \\
\hline under graduate & 9 & 24 & 7 & 40 \\
\hline $22.5 \%$ & & & & \\
\hline $60.0 \%$ & $17.5 \%$ & $100.0 \%$ & & \\
\hline Graduate & 13 & 47 & 16 & 76 \\
\hline $17.1 \%$ & & & & \\
\hline $61.8 \%$ & $21.0 \%$ & $100.0 \%$ & & \\
\hline post graduate & 6 & 6 & 22 & 34 \\
\hline $17.6 \%$ & & & & \\
\hline $17.6 \%$ & $64.7 \%$ & $100.0 \%$ & & \\
\hline Total & 28 & 77 & 45 & 150 \\
\hline $18.7 \%$ & & & & \\
\hline $51.3 \%$ & $30.0 \%$ & $100.0 \%$ & & \\
\hline
\end{tabular}

Chi-square $=15.74$, d.f. $=4$, Significance $=.035^{\star *}$, Gamma $=.284,{ }^{*}=$ Significant

Table 58 presents the association between education of the respondents and their political awareness. Chi-square value shows a significant association between education of the respondents and their political awareness. Gamma shows a 
positive relationship between the variables. It means educated respondents had more political awareness as compared to less educated. So the hypothesis "Higher the education higher the political awareness" is accepted.

\subsection{Hypothesis 3: Higher the income higher will be the political awareness}

Association between education of the respondents and their perception about socio-economic determinants of rural migrants in urban setting

\begin{tabular}{|c|c|c|c|l|}
\hline \multirow{2}{*}{ Education } & \multicolumn{3}{|l|}{ Political awareness } & \multirow{2}{*}{ Total } \\
\hline & Low & & & \\
\hline Medium & High & & 10 & 42 \\
\hline $19.0 \%$ & 8 & 24 & & \\
\hline $57.1 \%$ & $23.8 \%$ & $100.0 \%$ & & \\
\hline more than 30,000 & 14 & 32 & 23 & 69 \\
\hline $20.3 \%$ & & & & \\
\hline $46.4 \%$ & $33.3 \%$ & $100.0 \%$ & & \\
\hline more than 40,000 & 2 & 9 & 6 & 17 \\
\hline $11.8 \%$ & & & & \\
\hline $52.9 \%$ & $35.3 \%$ & $100.0 \%$ & & \\
\hline more than 50,000 & 4 & 12 & 6 & 22 \\
\hline $18.2 \%$ & & & & \\
\hline $54.5 \%$ & $27.3 \%$ & $100.0 \%$ & & \\
\hline Total & 28 & 77 & 45 & 150 \\
\hline $18.7 \%$ & $51.3 \%$ & $30.0 \%$ & $100.0 \%$ & \\
\hline
\end{tabular}

Chi-square $=2.20$, d.f. $=6$, Significance $=.900-N S$, Gamma $=.070$, NS $=$ Non-Significant

Table 59 presents the association between family income of the respondents and their political awareness. Chi-square value shows a non-significant association between family income of the respondents and their political awareness. Gamma shows a positive relationship between the variables. It means family income respondents had no impact on their political awareness. So the hypothesis "Higher the income higher will be the political awareness" is rejected.

\section{Conclusion}

During the statistical analysis in previous chapter and the resulting, discussions, his study recognized the following conclusion.

In this research, I investigated that majority were belonged to joint family system. Majority of the respondents were females. Mostly respondents were single. The occupations of mostly respondent's fathers were having govt.jobs. Mostly respondents were having graduate education. Mostly respondents have easy access to media. They know about political awareness. Majority respondent watch to like news channels. They watch mostly critical analysis type talk shows. Mostly respondents were fairly satisfied with the democracy working in Pakistan. Majority of the respondents agree that news channels promote political awareness in youth. Majority of the respondents like Imran Khan as famous political leader. Media is a major source of information about politics. Finally it is concluded that there a major roll of talk shows upon youth in creating awareness about politics.

\section{Recommendations}

1. Talk shows should give us political awareness

2. We should give our full attention to political talk shows and news channels so that we have awareness about condition of our country.

3. We should give our feedback about political talk shows that they know about our ideas and thinking and what we want. 
4. Our mostly talk shows base on critiques, they should be changed their shows topics in education and political awareness of youth specially.

5. Mostly talk shows topics hyper the people and gave them tensions they should b change their styles and decisions topics.

6. Talk shows should not fever to their favourite party.

7. Talk shows also should not leg pulling to their favourite opposite party.

8. People should remain calm during the participating in talk shows.

9. Talk shows should give correct information.

10. Talk shows should give solutions about the problem after discussion.

\section{References}

Ahmad Qureshi, (2012). Politics Portal. Retrieved 7 April 2012.

Anonymous (2011).Effects of television talk shows essay research paper

Ayesha Jamil 5 april2010 Political Talk Shows: Are They Making Or Breaking The Country?

Bahl, $v$ (2010). television talk shows

Barbara, Osborn( 2000). In Defense of Talk Show Politics.

Barr, N. (2004). Problems and definition of measurement. In Economics of the welfare state. New York: Oxford University Press. pp. 121-124

Bhantnagar. (2012).No party can have a shot at forming a government without having sufficient roots in rural Pakistan. University of Columbia

Blaikie,N, (2003),Analyzing quantitative data:From Description to explain ,SAGE publication.

Bourdieu, pierre.1983."The Forms of capital."Pp.241 58 in the Handbook of theory and research for the sociology of Education, edited by JhonG.Richardson.NewYork:Greenwood press

Burn\&Grove, ascited by Cormack, questionnaire Design: http //www.fortunecity.com /Greenfield/grizzly/432/rra2.htm April 10, 1991

Burn\&Grove, ascited by Cormack, questionnaire Design: http //www.fortunecity.com/Greenfield/grizzly/432/rra2.htm April 10, 1991

Chaudhry, S.M and S.Kamal 1996.Introduction to Statistical Theory Part-II.Ch.No.14 MarkaziKutabKhana, Urdu Bazaar Lahore,

Chaudhry, S.M and S.Kamal 1996.Introduction to Statistical Theory Part-II.Ch.No.14 MarkaziKutabKhana, Urdu Bazaar Lahore,

Data as of April 1994; Source: Library of Congress Country Studies(Pakistan and Islamic politics)

Diana Damean About the author: PhD candidate, Faculty of History and Philosophy, Babes-Bolyai University, Cluj, Romania. E-mail: diana28d@yahoo.com

Diana, Damean About the author: PhD candidate, Faculty of History and Philosophy, Babes-Bolyai University, Cluj, Romania

Ehrenreich, b (2010). "The role of talk shows"

Frisby, C. M. (1997, December). "WHEN BAD THINGS HAPPEN" THE SELF-ENHANCING EFFECT OF WATCHING TELEVISION TALK SHOWS." An Abstract of the Dissertation Presented to the Graduate School of the University of Florida in Partial Fulfillment of the requirements for the Degree of Doctor of Philosophy. Chairman: Dr. Michael F. Weigold

Frisby, C. M. (1998, August). "Can Social Comparison Theory Explain Viewer Fascination with TV Talk Shows?" A manuscript accepted for presentation at theAEJMC annual convention to be held in Baltimore, Maryland

Gay, L.R. (1996).Educational research: Competencies for analysis and application .Upper Saddle River, NJ: Merill

Gay, L.R. (1996).Educational research: Competencies for analysis and application .Upper Saddle River, NJ: Merill

Good and Hatt, 1952. Methods in social research, The University of Chicago Press

Good and Hatt, 1952. Methods in social research, The University of Chicago Press

Govt. of Pakistan, 1998 Census report of Pakistan, Population census Organization,

Govt. of Pakistan, 1998 Census report of Pakistan, Population census Organization,

Govt. of Pakistan, 2009 Census report of Pakistan, Population census organization statistics division, Islamabad

Govt. of Pakistan, 2009 Census report of Pakistan, Population census organization statistics division, Islamabad

Mahboob A. Khawaja, PhD ( July 27, 2012) Pakistan New Generation Looks for Change

Maliha, Fatima (2012). Fatima argues that media's role is very important nowadays. Pakistan is facing a lot of problems like corruption, inflation, load shedding, target killing etc. Media's duty is to show the truth but it should not always portray the negative aspects of our country.

MuznaShakeel, ( 2012): An Article On "The Role of Media in today's World".,Daily The Dawn Newspaper Pakistan. March 12, 2012.

Muzna, Shakeel (2012). An Article On "The Role of Media in today's World",,Daily The Dawn Newspaper Pakistan. March 12, 2012.

Naveed, Javaid (2012). International Islamic University, Islamabad A Conference on "Role of Media In Pakistan." Good Analysis 04/16/2012. NaveedJavaid (2012).

Neuman, 2001.Social Research Methods

Neuman, 2001.Social Research Methods

Neuman, w. I. (2006).social research method: qualitative and quantitative approaches dorling Kindersley pvt. Ltd.

NIPS, 2005, Publication of National Institute of Population Studies, Pakistan, 2005

NIPS, 2005, Publication of National Institute of Population Studies, Pakistan, 2005 
Oxford University (Hillton 2007)

Pakistan: The Imran Khan Phenomeno, AryamanBhatnagar(5 January 2012) Pakistan Press Foundation (PPF) In Collaboration with NED 3-Day Consultative Workshop with Media Professionals \& CSOs on "Current Political Scenario and the Role of Media"(June 17th, 2012)

Pakistani Talk Shows (Monday, July 4, 2011) Articles, Education, Politics By James Crabtree

Political parties and terrorBy Khaled Ahmed Published: June 9, 2012

Political parties: then and nowBy Yaqoob Khan BangashPublished: June 4, 2012, Published in The Express Tribune, June $5^{\text {th }}, 2012$.

Richard Huff and Richard Huff (1994).New York Daily News

Rockmouth (2005)."Effects of talk shows" p810.

Shirkey, Clay (2008). Here Comes Everybody. Penguin. p. 328. ISBN 978-1-59420-153-0.

Stebbins, Robert A. (2001).Exploratory Research in Social Sciences .Sage Publications

Stebbins, Robert A. (2001). Exploratory Research in Social Sciences .Sage Publications

Stelter, Brian (2010-09-30). "Anderson Cooper to Host Daytime Talk Show". NYTimes.com. Retrieved 2011-07-03.

Surender, Singh (2009). Youth. Canada's fourth annual Media Literacy Week, November 2-6, (2009)

The Nation Newspaper Pakistan, A article on "The Role of Media In Pakistan". . (Maliiha Fatima Saeed) 2012.

Tosh, hegel: The Pursuit of History, 2nd edition, London Group UK Limited, USA, 1991, pg.74

TV channels In Pakistan: Breaking News Without Substance (Qurat-ul-Ain on February 5, 2010)

VoyezFrancais: Book on "Impact of media on children and Youth". Paediatr Child Health (2003) May-June; 8(5): 301-306.

Weber, Bruce. "Johnny Carson News - The New York Times". Topics.nytimes.com. Retrieved (2011-07-03)

Weigold, M. F. (1994, August). Gratification's of talk: Esteem \& affect related consequences of viewing television talk shows. A manuscript presented to the Mass Communication and Society Division, Association for Education in Journalism and Mass Communication Convention, Atlanta, GA. 
